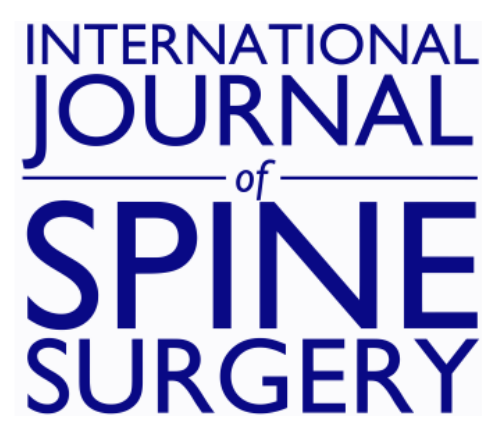

\title{
Heel Lift for Skiing to Compensate for Corrected Sagittal Vertical Axis After Spinal Surgery: A Case Report
}

Colleen Rentenberger, Stephan N. Salzmann, Jennifer Shue and Alexander P. Hughes

Int J Spine Surg 2021, 14 (s4) S33-S36

doi: https://doi.org/10.14444/7162

http://ijssurgery.com/content/14/s4/S33

This information is current as of April 26, 2023.

Email Alerts Receive free email-alerts when new articles cite this article. Sign up at:

http://ijssurgery.com/alerts

The International Journal of Spine Surgery

2397 Waterbury Circle, Suite 1,

Aurora, IL 60504, Phone: +1-630-375-1432 


\title{
Heel Lift for Skiing to Compensate for Corrected Sagittal Vertical Axis After Spinal Surgery: A Case Report
}

\author{
COLLEEN RENTENBERGER, MD, STEPHAN N. SALZMANN, MD, JENNIFER SHUE, MS, \\ ALEXANDER P. HUGHES, MD \\ Department of Orthopedic Surgery, Spine and Scoliosis Service, Hospital for Special Surgery, Weill Cornell Medical College, New York, New York
}

\begin{abstract}
Lateral lumbar interbody fusion (LLIF) and pedicle subtraction osteotomy are common procedures to correct adult spinal deformities. Little is known about returning postoperatively to a high-performance sport such as skiing after spinal surgery. We report a case of an alpine skier who underwent a LLIF procedure combined with a posterior corrective osteotomy and posterior instrumentation, who had difficulties returning to skiing postoperatively because of new spinal biomechanics. The case report describes the possible consequences of spinal sagittal deformity surgery on postoperative skiing. A 63-year-old man with a complex lumbar spinal surgery history showed severe adjacent segment degenerative spondylolistheses at L1-L2 and at L5-S1. A lateral approach at L1-L2 combined with a posterior corrective osteotomy at L3 and instrumentation from T10 to the pelvis were performed. At his 1-year follow up, he made excellent progress and returned to skiing. However, he reported that skiing did not feel the same, and his center of gravity felt as if it shifted backwards. Consequently, he placed a 2-cm wedge in his ski binding, which improved his skiing experience. Sagittal vertical axis changes after spinal surgery affect the biomechanics of the entire body. After surgery, the body's ligaments, muscles, and fascia adapt to the new body posture. Activities such as skiing, where body posture plays an essential role, are particularly affected by spine surgeries. Surgeons should discuss this issue before spinal surgery with patients, especially if patients are involved in high-intensity sports.
\end{abstract}

Lumbar Spine

Keywords: lateral lumbar interbody fusion, pedicle subtraction osteotomy, skiing, stance, sagittal vertical axis

\section{INTRODUCTION}

The importance of sagittal spinopelvic parameters in adult corrective surgeries has been described previously. ${ }^{1-4}$ To treat adult spinal deformities, lateral lumbar interbody fusion (LLIF) ${ }^{5}$ and pedicle subtraction osteotomy (PSO) ${ }^{6}$ are common procedures, especially for severe deformity cases. We report a unique case of an avid alpine skier who underwent a LLIF procedure combined with a PSO and posterior instrumentation and had difficulties skiing postoperatively.

\section{CASE PRESENTATION}

A 63-year-old man (body mass index $=30.9 \mathrm{~kg}$ / $\mathrm{m}^{2}$ ) presented with a complex lumbar spinal surgery history, including a lumbar decompression followed by a L2-5 posterior fusion 4 years prior. After a symptom-free period of 2 years, the patient experienced gradual mechanical low back pain with the sensation of a forward fixed posture. Other relevant surgical history included a bilateral total knee arthroplasty.

Radiographic examination showed severe adjacent segment degenerative spondylolisthesis and spinal stenosis at L1-L2 and at L5-S1 with severe bilateral foraminal stenosis and a positive sagittal vertical axis (SVA) or "flat black." Computed tomography (CT) scan showed solid fusion. The decision was made to perform a lateral approach at L1-L2 combined with a PSO at L3 and instrumentation from T10 to the pelvis, with the goal to decompress the spinal elements and balance the patient's center of gravity by matching lumbar lordosis (LL) within $10^{\circ}$ of pelvic incidence (PI).

The patient made excellent postoperative progress. By 1 year, he could ski, but he could not assume his usual posture because he felt his center of gravity shifted backwards. Consequently, the patient placed a heel lift in his ski binding, which improved his skiing performance significantly. 

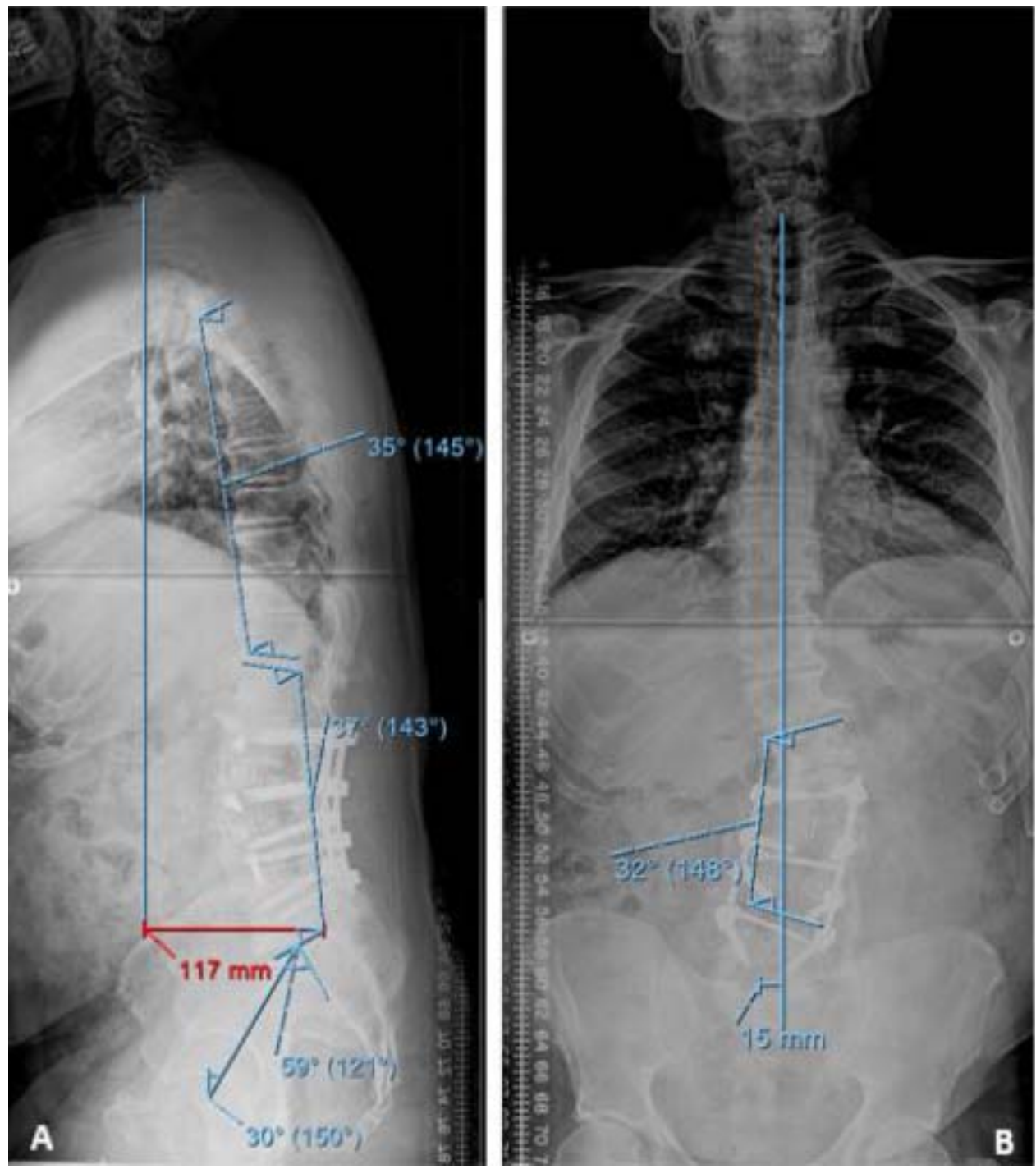

Figure 1. (A) Anteroposterior and (B) lateral lumbar $x$ rays performed 2 weeks before spine surgery, with spinopelvic parameters.

\section{DISCUSSION}

The relation between skiing and back pain is controversial. Although several studies ${ }^{7,8}$ showed that adolescent skiers are prone to back pain, the lifetime prevalence of back pain among ski instructors is similar to the general population. ${ }^{9}$ It is unclear how skiing contributed to our patient's back issues. However, the short recovery could be due to the patient's skiing history, as skiing along with strength training have a positive impact on lumbar spine bone density and muscle mass ${ }^{10}$ that are contributors to good spinal fusion outcomes.

The natural sagittal curves of the spine allow upright posture with minimal muscular effort. ${ }^{11} \mathrm{SVA}$ changes after spinal surgery affect the entire biomechanics of the body. Preoperatively, there was a lumbar coronal deformity and sagittal imbalance that required compensatory mechanisms by the pelvis (Figure 1). Postoperatively, the patient had a 6.6-cm decrease in SVA (Figure 2). Previous studies ${ }^{12}$ suggested that skiing could impact functional changes that affect global spinal balance. Therefore, the amount of SVA correction, although appropriate for nonskiers, might have been too much for the skiing patient who may have been accustomed to a greater SVA because of his skiing history.

After spinal surgery, the body's connective tissues adapt to the new postoperative posture. With skiing, where the stance slightly augmented the SVA by bringing the center of mass forward, SVA changes are even more pronounced. Spörri et $\mathrm{al}^{13}$ discussed how frontal bending, lateral bending, and torsion in the loaded trunk as it occurs in skiing may contribute 

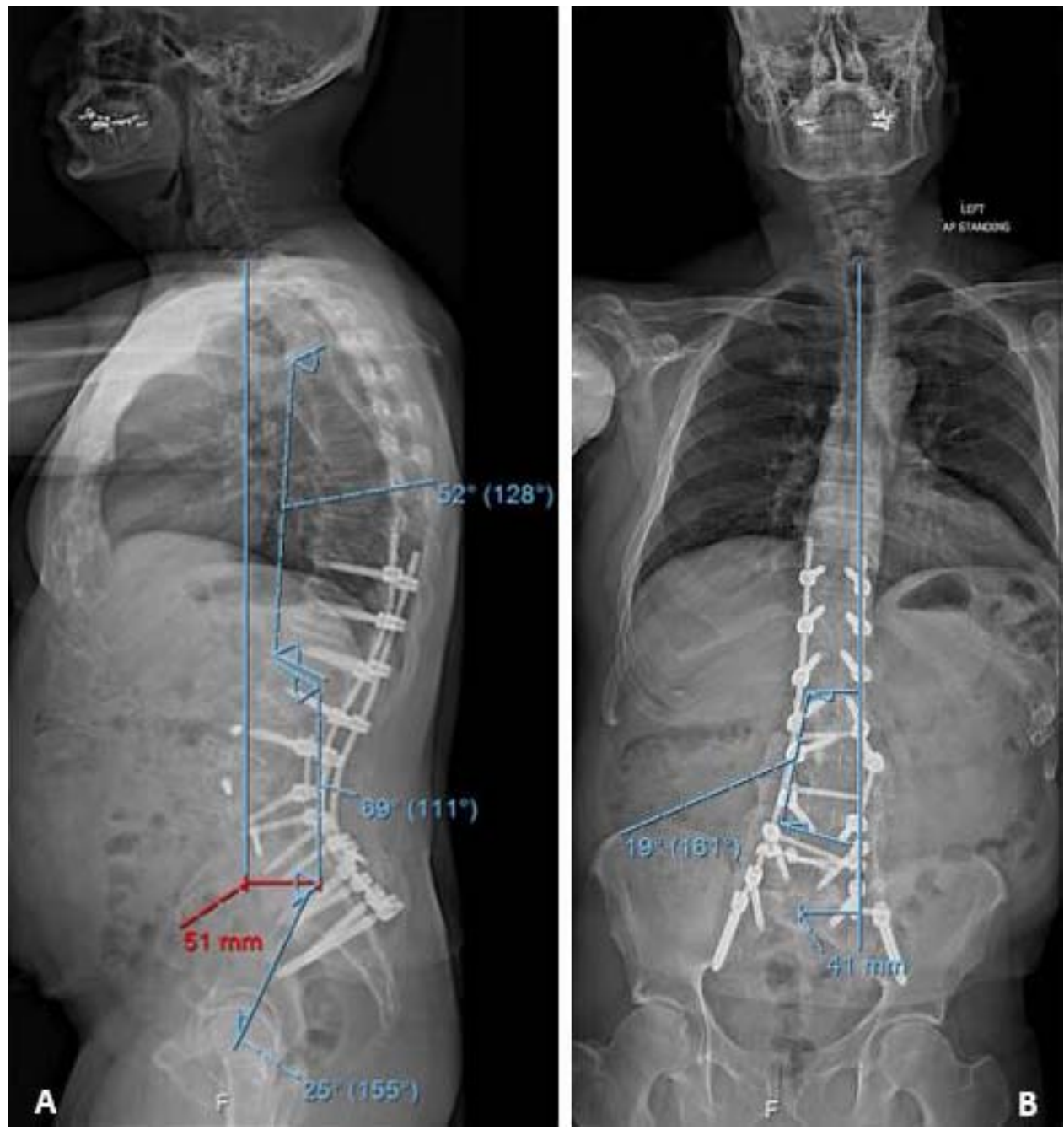

Figure 2. (A) Anteroposterior and (B) lateral lumbar $x$ rays performed 1 year after spine surgery with spinopelvic parameters.

to overuse back injuries in alpine ski racers. Therefore, skiing requires flexibility and muscle strength to withstand the high force of impact.

When the spine loses flexibility, other joints and muscle groups must compensate to achieve a similar range of motion. Elderly people with degenerative joints, in particular hips, might be less capable of compensatory mechanisms. Scheiber et al ${ }^{14}$ suggested that a greater knee angle might reduce perfusion, impeding substrate metabolism, resulting in more arduous skiing. Our patient, with a less flexible spine after surgery, most likely compensated with his lower extremities, making skiing more strenuous. Changing a learned muscular pattern, such as ventral muscle involvement for forward bending while skiing can be challenging for the elderly and require a significant amount of time and repetition. ${ }^{15}$ Therefore, it was easier for our patient to mechanically reproduce the forward bending posture by lifting the heels of his ski binding (Figure 3).

This is the first known report of an elderly patient who underwent spine surgery and experienced issues skiing that he addressed by mechanically shifting his center of gravity. Changes in SVA after spinal surgery can impact activities such as alpine skiing, where body posture plays an essential role. The potential postural and biomechanical changes that can affect spinal motion should be discussed with patients preoperatively. Surgeons should address the potential effects of spine surgery on patients' recreational activities, especially when high-intensity sports are involved, to establish realistic postoperative expectations. This is a unique case that may not be generalizable to all patients. However, surgeons can consider offering alternate solutions such as an adapted ski binding for such patients, 


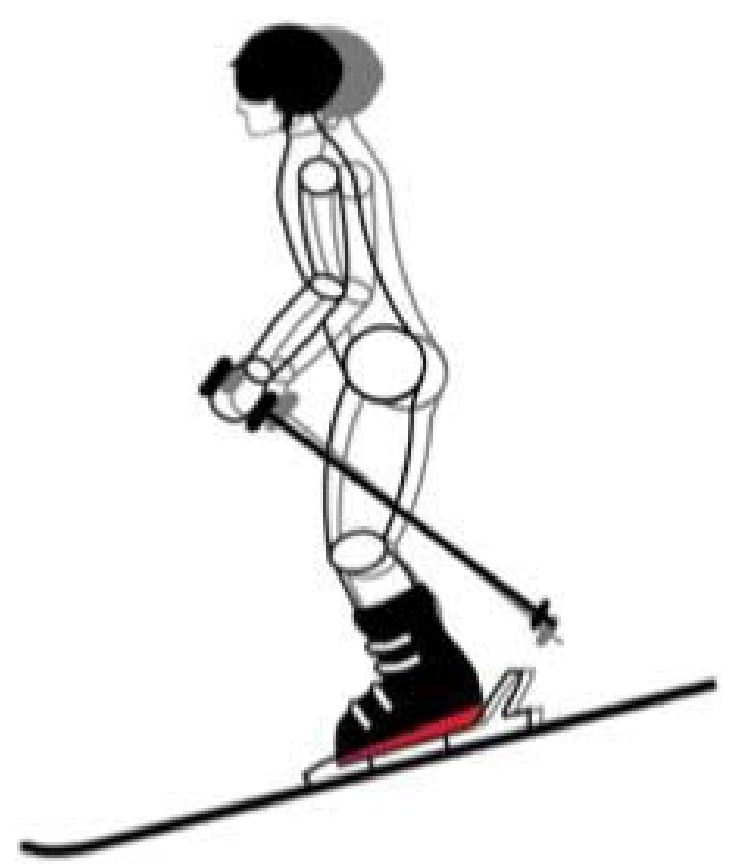

Figure 3. Schematic representation of the patient's postoperative posture with (black) and without (gray) an added heel lift to shift the center of gravity forward.

which can increase the postoperative quality of life and assist with resuming recreational sports

\section{KEY POINTS}

- Little is known about returning postoperatively to a high-performance sport such as skiing after spinal sagittal deformity surgery.

- Changes in SVA after spinal surgery can impact activities such as alpine skiing, where body posture plays an essential role.

- This is a case report of an elderly patient who underwent spine surgery and experienced issues skiing that he addressed by mechanically shifting his center of gravity.

\section{REFERENCES}

1. Kim Y, Bridwell K, Lenke L, et al. Sagittal thoracic decompensation following long adult lumbar spinal instrumentation and fusion to L5 or S1: causes, prevalence, and risk factors analysis. Spine (Phila Pa 1976). 2006;31(20):2359-2366.

2. Schwab F, Lafage V, Patel A, et al. Sagittal plane considerations and the pelvis in the adult patient. Spine (Phila Pa 1976). 2009;34(17):1828-1833.

3. Lafage V, Schwab F, Patel A, et al. Pelvic tilt and truncal inclination: two key radiographic parameters in the setting of adults with spinal deformity. Spine (Phila Pa 1976). 2009;34(17):E599-606.

4. Glassman SD, Bridwell K, Dimar JR, et al. The impact of positive sagittal balance in adult spinal deformity. Spine (Phila Pa 1976). 2005;30(18):2024-2029.
5. Pimenta L, Tohmeh A, Jones D, et al. Rational decision making in a wide scenario of different minimally invasive lumbar interbody fusion approaches and devices. J Spine Surg. 2018;4(1):142-155.

6. Kose KC, Bozduman O, Yenigul AE, et al. Spinal osteotomies: indications, limits and pitfalls. EFORT Open Rev. 2017;2(3):73-82.

7. Bergstrøm KA, Brandseth K, Fretheim S, et al. Back injuries and pain in adolescents attending a ski high school. Knee Surg Sports Traumatol Arthrosc. 2004;12(1):80-85.

8. Hangai M, Kaneoka K, Okubo Y, et al. Relationship between low back pain and competitive sports activities during youth. Am J Sports Med. 2010;38(4):791-796.

9. Peacock N, Walker JA, Fogg R, et al. Prevalence of low back pain in alpine ski instructors. J Orthop Sports Phys Ther. 2005;35(2):106-110.

10. Alvarez-San Emeterio C, Antunano NP-G, Lopez-Sobaler $\mathrm{AM}$, et al. Effect of strength training and the practice of alpine skiing on bone mass density, growth, body composition, and the strength and power of the legs of adolescent skiers. J Strength Cond Res. 2011;25(10):396-403.

11. Lamartina C, Berjano P, Petruzzi M, et al. Criteria to restore the sagittal balance in deformity and degenerative spondylolisthesis. Eur Spine J. 2012;21(Suppl 1):27-31.

12. Todd, C, Kovac P, Swärd A. et al. Erratum to: Comparison of radiological spino-pelvic sagittal parameters in skiers and non-athletes. J Orthop Surg Res 11, 148 (2016). doi:10. 1186/s13018-016-0485-8

13. Spörri J, Kröll J, Haid C, et al. Potential mechanisms leading to overuse injuries of the back in alpine ski racing: a descriptive biomechanical study. Am J Sports Med. 2015;43(8):2042-2048.

14. Scheiber P, Seifert J, Müller E. Relationships between biomechanics and physiology in older, recreational alpine skiers. Scand J Med Sci Sport. 2012;22(1):49-57.

15. Wolpert DM, Diedrichsen J, Flanagan JR. Principles of sensorimotor learning. Nat Rev Neurosci. 12. Epub ahead of print 2011. doi:10.1038/nrn3112

Disclosures and COI: This study was approved by the Institutional Review Board at the Hospital for Special Surgery. No funds were received in support of this work. The device(s)/ drug(s) is/are Food and Drug Administration approved or approved by corresponding national agency for this indication.

Corresponding Author: Alexander P. Hughes, MD, Spine Care Institute, Hospital for Special Surgery, 535 East 70th St, New York, NY 10021. Phone: (212) 774-2992; Fax: (212) 774-7062; Email: hughesa@hss.edu.

Published 11 February 2021

This manuscript is generously published free of charge by ISASS, the International Society for the Advancement of Spine Surgery. Copyright (C) 2020 ISASS. To see more or order reprints or permissions, see http://ijssurgery.com. 